\title{
Synthesis, Crystal Structure and Antimicrobial Activity of (E)-ethyl-4-(2-oxoacenaphthylen-1(2H)-ylideneamino) benzoate
}

\author{
Yi-Chen Chan ${ }^{1}$, Abdussalam Salhin Mohamed Ali $^{1 *}$, Melati Khairuddean ${ }^{1}$, Baharuddin Salleh ${ }^{2}$ \\ ${ }^{1}$ School of Chemical Sciences, Universiti Sains Malaysia, Penang, Malaysia; ${ }^{2}$ School of Biological Sciences, Universiti Sains Malay- \\ sia, Penang, Malaysia. \\ Email: "abdussalam@usm.my
}

Received March $3^{\text {rd }}, 2013$; revised April $5^{\text {th }}, 2013$; accepted April 15 ${ }^{\text {th }}, 2013$

Copyright (C) 2013 Yi-Chen Chan et al. This is an open access article distributed under the Creative Commons Attribution License, which permits unrestricted use, distribution, and reproduction in any medium, provided the original work is properly cited.

\begin{abstract}
A Schiff base, $(E)$-ethyl-4-(2-oxoacenaphthylen-1(2H)-ylideneamino)benzoate, (E4AB) had been synthesized in good yield by the acid-catalyzed condensation reaction of acenaphthenequinone and ethyl-4-aminobenzoate in methanolic solution. The synthesized compound was elucidated by elemental analysis (CHN), FTIR, ${ }^{1} \mathrm{H}-\mathrm{NMR},{ }^{13} \mathrm{C}-\mathrm{NMR}$ and single crystal X-ray diffraction. E4AB crystallized in the monoclinic crystal system with space group $P 2_{1} / c, Z=4, V=$ $1569.3(2) \AA^{3}$ and unit cell parameters $a=9.1589(8) \AA, b=21.2003(17) \AA, c=8.4502(7) \AA, \beta=106.972(2)^{\circ}$. The crystal structure of the compound is stabilized by intermolecular $\mathrm{C}-\mathrm{H} \cdots \mathrm{O}$ hydrogen bonds and weak intermolecular $\pi \cdots \pi$ interactions. The title compound had been tested for the antimicrobial activity against Bacillus subtilis (B. subtilis), Enterobacter and Fusarium oxysporum f. sp. Cubense (Foc) by disc-diffusion method. E4AB is relatively active against Foc which is a pathogen that cause Wilt disease (also well known as Panama disease) in banana plantation.
\end{abstract}

Keywords: Schiff Base; Acenaphthenequinone; Ethyl-4-aminobenzoate; Antimicrobial; Panama Disease

\section{Introduction}

Schiff base was first prepared by Hugo Schiff in 1864 [1]. Schiff bases are nitrogen analogues of aldehydes and ketones, having a carbon-nitrogen double bond in place of the carbonyl group [2]. Their formations constitute part of the broad class of condensation reaction. Schiff bases have been playing a pivotal role in the development of coordination chemistry and bioorganic chemistry with the acenaphthenequinone-based Schiff bases are widely synthesized due to their potential applications in various scientific areas [3-7].

Azomethines of acenaphthenequinone were found to have antimicrobial activities where El-Ayaan et al. [8] had reported that bis[N-(2,6-diisopropylphenyl)imino] acenaphthene was active against $S$. aureus, E. coli and $C$. albicans. Many of these microorganisms are pathogenic to animals and plants. B. subtilis and Enterobacter had been suggested to be associated with the sick building syndrome such as eye irritation, asthma, and throat infection among the building occupants [9-10] while Panama disease caused by Fusarium oxysporum f. sp. cubense

${ }^{*}$ Corresponding author.
(Foc) is regarded as one of the most dreadful disease threatening the banana production worldwide [11]. Hence, in this paper we report the synthesis and characterization of $(E)$-ethyl-4-(2-oxoacenaphthylen-1(2H)-ylideneamino)benzoate, (E4AB) and the antimicrobial activity of the title compound against B. subtilis, Enterobacter and Foc.

\section{Experimental}

In the preparation of $\mathrm{E} 4 \mathrm{AB}$, all the reagents were used as received. Melting point was determined by Stuart Scientific (UK) apparatus. Elemental analysis (CHN) was carried out on a Perkin Elmer Series II, 2400 analyzer. IR spectrum was recorded as $\mathrm{KBr}$ pellets on a Perkin Elmer System 2000 FT-IR spectrophotometer in the wavenumber range of $4000-400 \mathrm{~cm}^{-1}$. NMR spectra were recorded on a Bruker Avance III $500 \mathrm{MHz}$ spectrometer in ${ }^{D M S O}-\mathrm{d}_{6}$ using tetramethylsilane as an internal standard.

\subsection{Synthesis of E4AB}

Acenaphthenequinone $(0.182 \mathrm{~g}, 1 \mathrm{mmol})$, ethyl-4-ami- 
nobenzoate $(0.165 \mathrm{~g}, 1 \mathrm{mmol})$ and $30.0 \mathrm{~mL}$ of methanol were placed in $100 \mathrm{~mL}$ round bottom flask. The mixture was allowed to heat under reflux for overnight in the presence of formic acid. The solvent was removed to give the crude compound. Single crystal suitable for Xray crystallography was obtained after recrystallization from ethanol. Yield: $73 \%$. m.p.: $211^{\circ} \mathrm{C}-212^{\circ} \mathrm{C}$. Anal. Calcd for $\mathrm{C}_{21} \mathrm{H}_{15} \mathrm{NO}_{3}$ : C 76.60, H 4.56, $\mathrm{N} 4.26 \%$; found: C 76.94, H 4.33, N 4.38\%. Main IR bands $\left(\mathrm{KBr}, \mathrm{cm}^{-1}\right)$ : 2983 (w), 1729 (m), 1702 (s), 1666 (m), 1600 (s), 1275 (s), 1237 (m), 1107 (m), 1014 (m), 781 (m). ${ }^{1} \mathrm{H}-\mathrm{NMR}$ $500 \mathrm{MHz},\left(\mathrm{DMSO}-\mathrm{d}_{6}, \mathrm{ppm}\right): \delta 1.37\left(3 \mathrm{H}, \mathrm{t}, \mathrm{CH}_{3}\right), 4.36$ $\left(2 \mathrm{H}, \mathrm{q}, \mathrm{CH}_{2}\right), 6.79(1 \mathrm{H}, \mathrm{d}, \mathrm{H} 8), 7.22(2 \mathrm{H}, \mathrm{d}, \mathrm{H} 14), 7.59$ $(1 \mathrm{H}, \mathrm{t}, \mathrm{H} 7), 7.93(1 \mathrm{H}, \mathrm{t}, \mathrm{H} 3), 8.11(2 \mathrm{H}, \mathrm{d}, \mathrm{H} 15), 8.16(1 \mathrm{H}$, d, H2), $8.22(1 \mathrm{H}, \mathrm{d}, \mathrm{H} 6), 8.39(1 \mathrm{H}, \mathrm{d}, \mathrm{H} 4) .{ }^{13} \mathrm{C}-\mathrm{NMR}$ (ppm): $\delta 14.21,60.67,117.77,121.94,123.19,126.19$, $126.39,128.45,128.62,129.83,130.15,130.66,130.90$, 132.41, 142.68, 154. 98, $158.96(\mathrm{C}=\mathrm{N}), 165.39(\mathrm{C}=\mathrm{O})$, $188.32(\mathrm{C}=\mathrm{O})$.

\subsection{Crystal Structure Determination}

Crystal data was collected using Bruker APEXII DUO area-detector diffractometer with graphite monochromated $\mathrm{MoK} \alpha$ radiation at a detector distance of $50 \mathrm{~mm}$ and collected under $100 \mathrm{~K}$ using Oxford Cryosystem Cobra low temperature attachement [12]. The cell refinement and data reduction were performed using SAINT program [13] and the empirical absorption correction was performed using the SADABS program [13]. The structure was solved by direct methods and refined by leastsquares using SHLEXTL software package [14]. All non-hydrogen atoms were refined anisotropically. All hydrogen atoms were placed in idealized position, and refined using a riding model. The details of the crystal data and structure refinements are given in Table 1.

\subsection{Antimicrobial Activity Determination}

$\mathrm{E} 4 \mathrm{AB}$ was tested for the antibacterial activity against $B$. subtilis and Enterobacter by slight modification of the disc-diffusion method described by Murray et al. [15]. $0.1 \mathrm{~mL}$ of $10^{8} \mathrm{CFU} / \mathrm{mL}$ of bacteria suspension was streaked evenly onto the agar containing Petri plate. The plate was then allowed to air dry in laminar flow. E4AB was dissolved in DMSO to get 1000,500 and $250 \mu \mathrm{g} / \mathrm{mL}$ concentrations of the compound. Four sterilized filter paper discs (diameter $7 \mathrm{~mm}$ ) were placed at four equidistant places on the inoculated plate. $20 \mu \mathrm{L}$ of each concentration of the compound was spiked on the disc accordingly by using micropipette. Filter paper disc treated with DMSO was served as the control in the test. Lastly, the inoculated plate was allowed to air dry and incubated under room temperature $\left(25^{\circ} \mathrm{C} \pm 2^{\circ} \mathrm{C}\right)$ for 48 hours before the inhibition zone was recorded in diameter $(\mathrm{mm})$. Each test was conducted in triplicate. In the
Table 1. Crystal data, data collection and refinement parameters of $\mathrm{E} 4 \mathrm{AB}$.

\begin{tabular}{|c|c|}
\hline Compound & E4AB \\
\hline Empirical formula & $\mathrm{C}_{21} \mathrm{H}_{15} \mathrm{NO}_{3}$ \\
\hline Formula weight & 329.34 \\
\hline Temperature $(\mathrm{K})$ & 100 \\
\hline Wavelength $(\AA)$ & 0.71073 \\
\hline Crystal colour & Yellow \\
\hline Crystal shape & Block \\
\hline Crystal size $(\mathrm{mm})$ & $0.50 \times 0.38 \times 0.13$ \\
\hline Crystal system & Monoclinic \\
\hline Space group & $P 2_{1} / c$ \\
\hline \multirow[t]{2}{*}{ Lattice constants } & 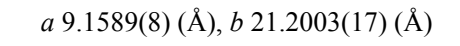 \\
\hline & $c 8.4502(7)(\AA), \quad \beta\left(^{\circ}\right) 106.972(2)$ \\
\hline$V\left(\AA^{3}\right)$ & $1569.3(2)$ \\
\hline$Z$ & 4 \\
\hline$D_{\text {calc }}\left(\mathrm{g} \mathrm{cm}^{-3}\right)$ & 1.394 \\
\hline$\mu\left(\mathrm{mm}^{-1}\right)$ & 0.094 \\
\hline$F(000)$ & 688 \\
\hline$\theta$ range & $1.92-35.11$ \\
\hline Limiting indices & $-14 \leq h \leq 14 ;-34 \leq k \leq 33 ;-11 \leq l \leq 13$ \\
\hline Completeness to $\theta(\%)$ & 98.8 \\
\hline Reflections collected & 6885 \\
\hline Goodness of fit & 1.022 \\
\hline Refined parameters & 227 \\
\hline$R_{1}[I>2 \sigma(I)]$ & 0.0436 \\
\hline$w R_{2}[I>2 \sigma(I)]$ & 0.1196 \\
\hline$R_{1}, w R_{2}$, all data & $0.0527 / 0.1275$ \\
\hline
\end{tabular}

antifungal activity against $F o c$ the same method as described for antibacterial activity was applied except for the amount of fungal suspension and incubation period used which were $1 \mathrm{~mL}$ of $1 \times 10^{4}$ spore $/ \mathrm{mL}$ suspension and seven days, respectively.

\section{Results and Discussion}

\subsection{Description of the Crystal Structure}

In E4AB (Figure 1), the acenaphthylenone moiety is essentially planar, with atom $\mathrm{C} 10$ deviates from the mean plane formed by a maximum deviation of -0.057 (1) $\AA$. Nevertheless, the whole molecule is not planar, as indicated by the dihedral angle between the mean planes through the acenaphthylenone moiety and phenyl ring being $74.44(3)^{\circ}$. The ethyl formate group is slightly inclined at a dihedral angle of $12.01(5)^{\circ}$ with respect to the attached phenyl ring. In the crystal packing (Figure 2), adjacent molecules are interconnected into one-dimensional hydrogen-bonded chains propagating along the $a$ axis via intermolecular $\mathrm{C}-\mathrm{H} \cdots \mathrm{O}$ hydrogen bonds 


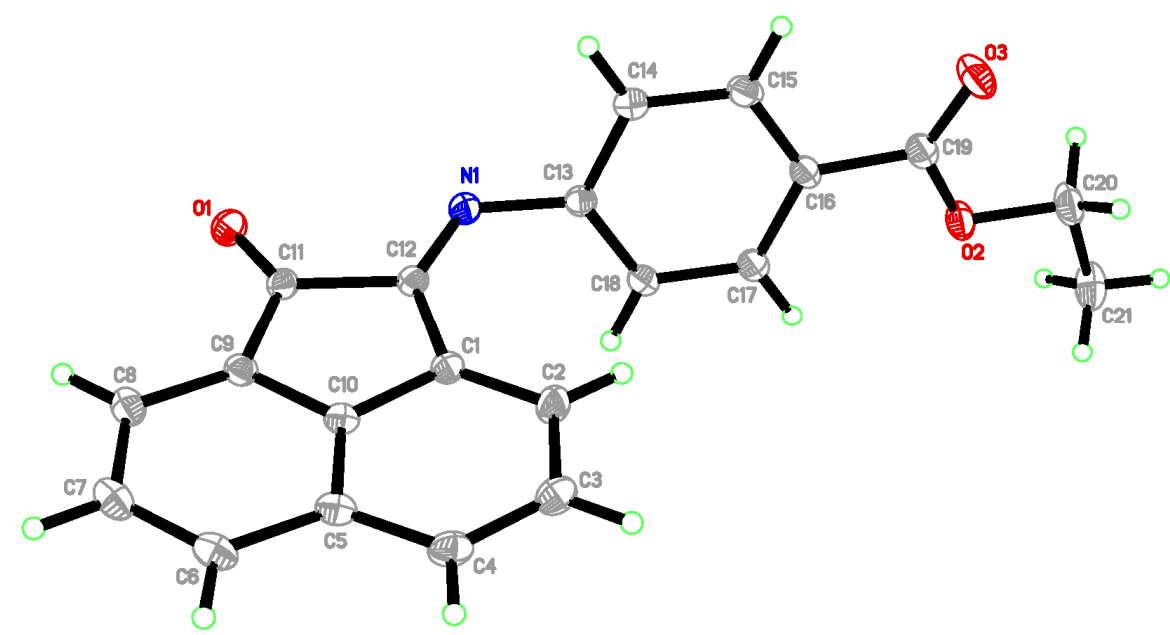

Figure 1. Molecular structure of E4AB. The non-hydrogen atoms are drawn as thermal ellipsoids with $50 \%$ probability displacement level.

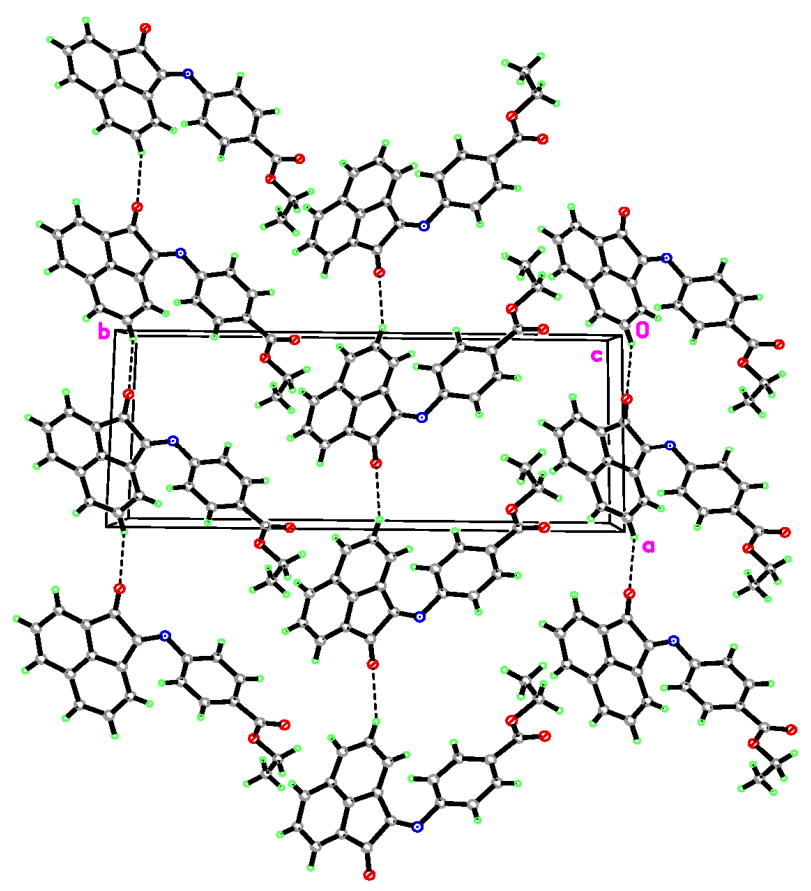

Figure 2. Crystal packing of E4AB, showing molecules being interconnected into one-dimensional chains along the $a$ axis. Intermolecular hydrogen bonds are shown as dashed lines.

[C $\cdots$ O distance of 3.4010(11) $\AA$ ]. Further stabilization of the crystal packing is provided by weak intermolecular $\pi \cdots \pi$ aromatic stacking interactions [centroid-centroid distance of 3.7102(6) $\AA$ ] involving the C5-C10 phenyl ring. The selected bond lengths and bond angles are given in Table 2.

\subsection{FT-IR Spectrum}

$\mathrm{E} 4 \mathrm{AB}$ displays two stretching bands at 1729 and 1702 $\mathrm{cm}^{-1}$ which are corresponded to the $\mathrm{C}=\mathrm{O}$ stretching vi-
Table 2. Selected bond angles $\left(^{\circ}\right)$ and bond lengths $(\AA)$ of E4AB.

\begin{tabular}{cccc}
\hline Bond & Angle ( $\left.{ }^{\circ}\right)$ & Bond & Length $(\AA)$ \\
\hline C19-O2-C20 & $116.04(7)$ & O1-C11 & $1.2112(9)$ \\
O1-C11-C12 & $124.87(7)$ & O2-C20 & $1.4529(10)$ \\
N1-C12-C11 & $118.84(7)$ & N1-C12 & $1.2705(10)$ \\
C18-C13-N1 & $121.36(7)$ & C16-C19 & $1.4836(11)$ \\
C17-C16-C19 & $122.22(7)$ & O2-C19 & $1.3411(10)$ \\
O3-C19-C16 & $123.93(8)$ & O3-C19 & $1.2110(10)$ \\
C12-N1-C13 & $121.82(7)$ & N1-C13 & $1.4087(10)$ \\
N1-C12-C1 & $134.44(7)$ & C11-C12 & $1.5429(10)$ \\
C14-C13-N1 & $118.33(7)$ & & \\
C15-C16-C19 & $118.17(7)$ & & \\
O3-C19-O2 & $123.63(8)$ & & \\
O2-C19-C16 & $112.43(7)$ & & \\
\hline
\end{tabular}

brations of the ester and the ketone, respectively [16]. Meanwhile the $v(\mathrm{C}=\mathrm{N})$ band is assigned to an absorption at $1666 \mathrm{~cm}^{-1}$ [17]. The characteristic aromatic ring $\mathrm{C}=\mathrm{C}$ stretching frequency is observed at $1600 \mathrm{~cm}^{-1}$ [2]. In the IR spectrum of E4AB, the C-H stretch of $s p^{3}$ hybrid carbon atom appears at $2983 \mathrm{~cm}^{-1}$.

\section{3. ${ }^{1}$ H-NMR Spectroscopy}

${ }^{1} \mathrm{H}-\mathrm{NMR}$ spectrum of E4AB is shown in Figure 3. A triplet at $\delta 1.37 \mathrm{ppm}$ and a quartet at $\delta 4.36 \mathrm{ppm}$ are assigned to $\mathrm{H} 19$ and $\mathrm{H} 18$, respectively. $\mathrm{H} 8$ which is ortho magnetically coupled to $\mathrm{H} 7$ appears as a doublet at $\delta$ $6.79 \mathrm{ppm}$ with a coupling constant of $7.5 \mathrm{~Hz}$. Meanwhile the doublet at $\delta 7.22 \mathrm{ppm}$ is attributed to $\mathrm{H} 14$ which is coupled to $\mathrm{H} 15$ ( $\delta 8.11 \mathrm{ppm})$. $\mathrm{H} 7$ and $\mathrm{H} 3$ are observed as triplets at $\delta 7.59$ and $7.93 \mathrm{ppm}$, respectively. $\mathrm{H} 7$ is coupled to $\mathrm{H} 8$ and $\mathrm{H} 6$ while $\mathrm{H} 3$ is coupled to $\mathrm{H} 2$ and $\mathrm{H} 4$ 


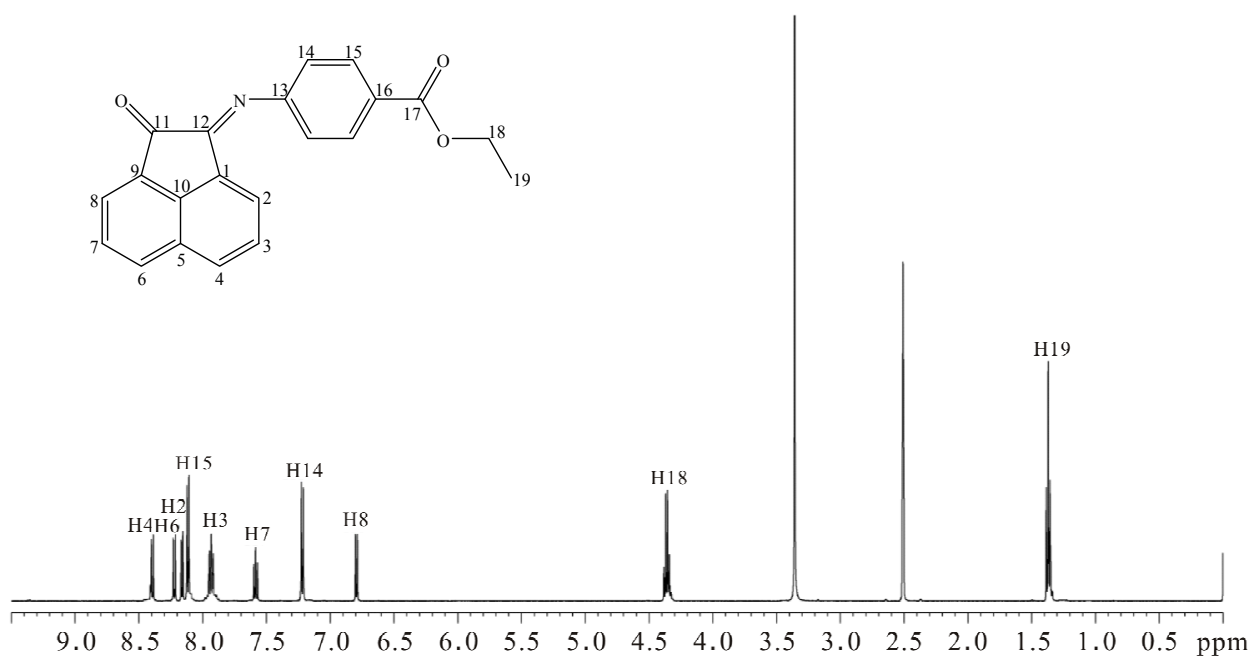

Figure 3. ${ }^{1} \mathrm{H}$-NMR spectrum of E4AB.

where $\mathrm{H} 2, \mathrm{H} 4$ and $\mathrm{H} 6$ are assigned to doublets at $\delta 8.16$, 8.39 and $8.22 \mathrm{ppm}$, respectively. The assignment of naphthalene protons to the corresponding signals are in agreement with the previously reported observations by Wang et al. [18] and Yang et al. [19].

\subsection{Antimicrobial Activity}

The antimicrobial activity of the title compound in DMSO solution was assayed against two bacteria and one fungus by disc-diffusion method employing 1000 , 500 and $250 \mu \mathrm{g} / \mathrm{mL}$ concentrations of the compound. The effectiveness of an antimicrobial agent in sensitivity testing is based on the size of zone of inhibition. The diameter of the zone is measured to the nearest millimeter. The result (Table 3) shows that at higher concentration, the Gram-negative bacterium (Enterobacter) is more sensitive towards E4AB than the Gram-positive bacterium (B. subtilis). E4AB also exhibits relatively potent inhibitory activity against Foc.

\section{Conclusion}

(E)-ethyl-4-(2-oxoacenaphthylen-1(2H)-ylideneamino)be nzoate, E4AB had been synthesized in good yield. Melting point determination was performed to check the purity of the compound. Results obtained from the elemen

Table 3. Antimicrobial activity of E4AB.

\begin{tabular}{cccc}
\hline \multirow{2}{*}{$\begin{array}{c}\text { Concentration of } \\
\text { E4AB }(\boldsymbol{\mu g} / \mathbf{m L})\end{array}$} & \multicolumn{3}{c}{ Diameter of inhibition zone (mm) } \\
\cline { 2 - 4 } & B. subtilis & Enterobacter & Foc \\
\hline 1000 & $9.0 \pm 0.0$ & $13.7 \pm 0.58$ & $12.3 \pm 0.58$ \\
500 & $8.3 \pm 0.58$ & $12.0 \pm 0.0$ & $9.3 \pm 0.58$ \\
250 & $8.0 \pm 0.0$ & NA & $8.0 \pm 0.0$ \\
\hline
\end{tabular}

$\mathrm{NA}=$ not active tal, spectral (FTIR, NMR) and X-ray crystallography had confirmed the proposed structure of the title compound. $\mathrm{E} 4 \mathrm{AB}$ was found to be able to inhibit B. subtilis, Enterobacter and Foc.

\section{Acknowledgements}

The authors would like to thank Universiti Sains Malaysia-Science Fund Grant No. 1001/PKIMIA/ 823003 and RU Grant No. 1001/PKIMIA/811196 for the financial support of this work.

\section{REFERENCES}

[1] R.-B. Xu, N. Zhang, H.-Y. Zhou, S. P. Yang, Y.-Y. Li, D.-H. Shi, W.-X. Ma and X.-Y. Xu, "Synthesis, Crystal Structure and Antibacterial Activity of $N, N$ '-bis(4-metoxy-benzylidene)-1,4-bis(3-aminopropyl)piperazine," Journal of Chemical Crystallography, Vol. 42, No. 9, 2012, pp. 928-932. doi:10.1007/s10870-012-0338-1

[2] L. G. Wade, "Organic Chemistry," 6th Edition, Pearson Prentice Hall, Upper Saddle River, 2005.

[3] R. J. Maldanis, J. S. Wood, A. Chandrasekaran, M. D. Rausch and J. C. W. Chien, "The Formation and Polymerization Behaviour of $\mathrm{Ni}$ (II) $\alpha$-Diimine Complexes Using Various Aluminium Activators," Journal of Organometallic Chemistry, Vol. 645, No. 1-2, 2002, pp. 158-167. doi:10.1016/S0022-328X(01)01340-7

[4] I. Mhaidat, J. A. Mergos, S. Hamilakis, C. Kollia, Z. Loizos, A. Tsolomitis and C. T. Dervos, "One-Stage Synthesis of Poly[( $p$-phenylimino)-acenaphthene], a New Macromolecular Material with Interesting Electric Properties," Materials Letters, Vol. 63, No. 29, 2009, pp. 2587 2590. doi:10.1016/j.matlet.2009.09.016

[5] Y.-G. Li, L. Pan, Z.-J. Zheng and Y.-S. Li, "Polymerization of Ethylene to Branched Polyethylene with Silica and Merrifield Resin Supported Nickel(II) Catalysts with $\alpha$-Diimine Ligands," Journal of Molecular Catalysis A: Chemical, Vol. 287, No. 1-2, 2008, pp. 57-64. 
doi:10.1016/j.molcata.2008.03.003

[6] G. W. Son, K. B. Bijal, D. W. Park, C. S. Ha and I. L. Kim, "Novel Nickel(II)-Based Catalysts for the Polymerization of Ethylene," Catalysis Today, Vol. 111, No. 34, 2006, pp. 412-416. doi:10.1016/j.cattod.2005.10.054

[7] M. C. Rodriguez-Argüelles, M. B. Ferrari, G. G. Fava, C. Pelizzi, G. Pelosi, R. Albertini, A. Bonati, P. P. Dall' Aglio, P. Lunghi and S. Pinelli, "Acenaphthenequinone Thiosemicarbazone and Its Transition Metal Complexes: Synthesis, Structure, and Biological Activity," Journal of Inorganic Biochemistry, Vol. 66, No. 1, 1997, pp. 7-17. doi:10.1016/S0162-0134(96)00146-8

[8] U. El-Ayaan, and A. A. M. Abdel-Aziz, "Synthesis, Antimicrobial Activity and Molecular Modelling of Cobalt and Nickel Complexes Containing the Bulky Ligand: Bis[N-(2,4-diisopropylphenyl)imino]acenaphthene," European Journal of Medicinal Chemistry, Vol. 40, No. 12, 2005, pp. 1214-1221. doi:10.1016/j.ejmech.2005.06.009

[9] P. L. Ooi and K. T. Goh, "Sick Building Syndrome: An Emerging Stress-Related Disorder," International Journal of Epidemiology, Vol. 26, No. 6, 1997, pp. 1243-1249. doi:10.1093/ije/26.6.1243

[10] M. J. Mendell, W. J. Fisk, K. Kreiss, H. Levin, D. Alexander, W. S. Cain, J. R. Girman, C. J. Hines, P. A. Jensen, D. K. Milton, L. P. Rexroat and K. M. Wallingford, "Improving the Health of Workers in Indoor Environments: Priority Research Needs for a National Occupational Research Agenda," American Journal of Public Health, Vol. 92, No. 9, 2002, pp. 1430-1440. doi:10.2105/AJPH.92.9.1430

[11] Jumjunidang, Riska and A. Soemargono, "Identification and Distribution of Fusarium Oxysporum f. sp. Cubense Isolates through Analysis of Vegetative Compatibility Group in Lampung Province, Indonesia," Journal of Engineering and Applied Sciences, Vol. 7, No. 4, 1990, pp.
279-284.

[12] J. Cosier and A. M. Glazer, "A Nitrogen-Gas-Stream Cryostat for General X-Ray Diffraction Studies," Journal of Applied Crystallography, Vol. 19, No. 2, 1986, pp. 105107. doi:10.1107/S0021889886089835

[13] Bruker, "APEX2, SAINT and SADABS," Bruker AXS Inc., Madison, 2009.

[14] G. M. Sheldrick, "A Short History of SHELX," Acta Crystallographica Section A, Vol. 64, No. 1, 2008, pp. 112-122. doi: $10.1107 / \mathrm{S} 0108767307043930$

[15] R. P. Murray, E. J. Baron, M. A. Pfaller, F. C. Tenover, and R. H. Yolken, "Manual of Clinical Microbiology," 6th Edition, ASM Press, Washington DC, 1995.

[16] J. Kovach, M. Peralta, W. W. Brennessel and W. D. Jones, "Synthesis and X-Ray Crystallographic Characterization of Substituted Aryl Imines," Journal of Molecular Structure, Vol. 992, No. 1-3, 2011, pp. 33-38. doi:10.1016/i.molstruc.2011.02.027

[17] K. M. El-Shaieb, "Condensation of 1-(Dicycanomethylene)acenaphthene-2-one with Aromatic Diamines," Journal of the Chinese Chemical Society, Vol. 55, No. 5, 2008, pp. 1150-1155.

[18] X. Y. Wang, J. N. Cui, W. M. Ren, F. Li, C. L. Lu and X. H. Qian, "Baker's Yeast Mediated Reduction of Substituted Acenaphthenequinones: Regio- and Eneatioselective Preparation of Mono-Hydroxyacenaphthenones," Chinese Chemical Letters, Vol. 18, No. 6, 2007, pp. 681-684. doi:10.1016/i.cclet.2007.04.022

[19] W. Yang, Z. Yin, Z. Li, J. He and J.-P. Cheng, "A New Acenaphthenequinone-Based Calyx[4]pyrrole: Synthesis, Structure and Anion Binding Study," Journal of Molecular Structure, Vol. 889, No. 1-3, 2008, pp. 279-285. doi:10.1016/j.molstruc.2008.02.014 